\title{
Pregnancy as public property: The experience of couples following diagnosis of a fetal anomaly
}

Background: Pregnant women find themselves subject to comments and questions from people in public areas. Normally, becoming 'public property' is considered friendly and is relatively easy for pregnant women to deal with. However, following diagnosis of a fetal anomaly, the experience of being public property can exacerbate the emotional turmoil experienced by couples.

Original research question: What is the experience of couples who continue pregnancy following the diagnosis of a fetal anomaly?

Method: The study used an interpretive design informed by Merleau-Ponty and this paper reports on a subset of findings. Thirty-one interviews with pregnant women and their partners were undertaken following the diagnosis of a serious or lethal fetal anomaly. Women were between 25 and 38 weeks gestation at the time of their first interview. The non-directive interviews were audiotaped, transcribed verbatim and the transcripts were thematically analysed.

Findings: A prominent theme that emerged during data analysis was that pregnancy is embodied therefore physically evident and 'public'. Women found it difficult to deal with being public property when the fetus had a serious or lethal anomaly. Some women avoided social situations; others did not disclose the fetal condition but gave minimal or avoidant answers to minimise distress to themselves and others. The male participants were not visibly pregnant and they could continue life in public without being subject to the public's gaze, but they were very aware and concerned about its impact on their partner.

Conclusion: The public tend to assume that pregnancy is normal and will produce a healthy baby. This becomes problematic for women who have a fetus with an anomaly. Women use strategies to help them cope with becoming public property during pregnancy. Midwives can play an important role in reducing the negative consequences of a woman becoming public property following the diagnosis of a fetal anomaly. 
KEYWORDS Public property; Fetal anomaly; Pregnancy; Embodiment; Phenomenology; Midwifery 
We are involved in the world and with others in an inextricable tangle

(Merleau-Ponty, 1945/1962, p. 528)

\section{Introduction}

As a naïve and excited student nurse touring my training hospital, I encountered a woman in labour and said 'What a beautiful day to have a baby'. She looked at me, a beaming 18-year-old straight from high school, and said 'My baby is dead'. I had no idea that birth and death could occur together. This mortifying and unforgettable event coupled with later experience as a midwife, led me to wonder how people assume pregnancy will result in a healthy baby. I also wondered why strangers feel free to comment on a women's pregnancy, in essence, treating her like public property. This paper explores how couples experience becoming public property after diagnosis of a serious or lethal fetal anomaly and in essence, articulates part of the answer to the overarching research question; what is the experience of couples who continue pregnancy following the diagnosis of a fetal anomaly?

\section{Literature Review}

In keeping with the nature of phenomenological studies, the review process was guided by integrative methods ${ }^{1}$ which allow for inclusion of experimental and non experimental research, theoretical and empirical literature. Multiple databases were used in the search process using the keywords, pregnancy (and variances) combined with public, property, midwifery and embodiment.

The search yielded feminist and sociological research articles and commentaries on the female body as a fetal vessel subject to public scrutiny, commentary and control ${ }^{2-8}$. Social and feminist literature also outlined the pervasive social and medical expectations related to how women act in order to be 'good mothers' who behave appropriately ${ }^{9,10}$. Although these articles demonstrated depth and breadth they could only serve as a background for understanding the phenomenon investigated, as none related to the woman’s experience following a diagnosis of a fetal anomaly. .

If it were not for a one page commentary by the midwife, Jane Bainbridge ${ }^{11}$ identifying how pregnant women receive unsolicited advice and comments as part of being subjected to the public 
gaze, the concept of pregnancy as public property would be virtually invisible in the midwifery specific literature. Bainbridge ${ }^{11}$ utilised the term 'public property' to describe how a woman's pregnancy becomes everybody's business. She describes how even strangers feel entitled to touch a woman's pregnant abdomen, make comments, ask unsolicited questions and give advice ${ }^{11}$.

Literature related to perinatal hospice care included one article which briefly noted that pregnancy may be a shared public event and couples may face questions in public settings. ${ }^{12}$ Research on couples following diagnosis of a lethal fetal condition has found parents may find regular childbirth classes and clinical waiting rooms full of healthy pregnant women distressing. ${ }^{13,14}$. RamerChrastek and Thygeson ${ }^{15}$ note ‘innocent questions’ may be painful for parents. However, despite brief statements recognising these difficulties, the concept of pregnancy as public property following diagnosis of a fetal anomaly has not been explored in depth. This article seeks to address this gap through documenting couples' experiences of the public gaze following the diagnosis of a fetal anomaly.

\section{Methodology and Method}

The philosophical foundation of this study is Merleau-Ponty's phenomenology which outlines the embodied nature of human perception ${ }^{16}$. This means a person is influenced and shaped by culture, society and interactions between self and others. Hence, Merleau-Ponty argues that bracketing, the suspending of the researchers views, emotions and backgrounds is impossible ${ }^{17-19}$. Using bracketing would breach the tenets of Merleau-Ponty's phenomenology and align with the reductive ideology of Cartesian disembodiment ${ }^{20}$ which is rejected by the midwifery ethos of holistic care. Phenomenology seeks to uncover the elusive features of reality as lived and experienced in a shared world ${ }^{21}$.

Couples who chose to continue pregnancy after their unborn babies were diagnosed with serious or lethal anomalies were recruited from a maternal-fetal medicine clinic in Washington State, USA between 2006-2009. Purposive sampling was used as the participants had to be living the phenomena under investigation in order to know and describe their experience. Mapp ${ }^{20}$ defends 
purposive sampling for phenomenological studies because it enables an in-depth understanding of experience. Following informed consent, the 31 participants were interviewed during their pregnancy and after birth (20 women and 11 partners).

Female participants were aged from 18-45 years with an average age of 34.1 years. The ages of male participants were not collected but all were of a similar age to their partner. Women were between 25 and 38 weeks gestation at the time of the first interview. Many women had suffered miscarriages or infertility, only 6 were multigravidas. Three quarters of the women, 15 out of 20 proceeded to have caesarean sections. Fetal anomaly diagnoses, prognosis and outcome are outlined in table 1. Four women had a twin pregnancy; in each twin pregnancy one fetus did not have a serious anomaly. Only one woman had both twins survive, one of these twins required a series of major surgeries including a colostomy. The three remaining couples with twins had one surviving infant.

The unstructured interviews occurred wherever it was most convenient for participants. All interviews occurred in participant's homes, the maternal-fetal medicine clinic or the hospital room (for women who were inpatients or parents with a hospitalised baby during the second interview). Initially the goal was to interview couples separately but this proved impractical and sometimes the partner was in the room or coming in and out, or engaged in care of the baby or other children. The researcher dressed in neat casual clothes to appear friendly and non-threatening. After each interview, notes were taken to consolidate and work through the process and provide an audit trail.

The interviews were audio-taped, transcribed verbatim and then read in detail multiple times to enable data immersion; the transcripts were analysed for themes using several methods which are outlined to provide a transparent decision trail. First, the transcripts were analysed in a table where an interpretive notation was written next to the transcript. Second, using NVivo ${ }^{22}$ transcripts were read again and placed in nodes containing themes and annotated with detailed memos. Attention was paid to both convergence and divergence. The nodes were then combined into four major connected 
themes. The transcripts were then physically cut and sorted multiple times until they coalesced into major themes and sub themes.

Consideration was given as to whether member checking (returning transcripts to participants) should be used to enhance rigour but due to the sensitive nature of the research, this was considered ethically inappropriate. However, during the face-to-face interviews participants were asked to clarify any information that was unclear. Non-directive interviews meant the researcher followed the participants thread by using gentle, conversational encouragement. The nature of this research demanded the researcher follow the participants' construction of their experiences as they narrated them ${ }^{23}$. Rigour was enhanced by utilising direct quotes, enabling the participants to express themselves directly in the findings section and this allows the reader to judge the appropriateness and depth of interpretation. Data from in-depth interviews answered the question, 'What is your experience of pregnancy following diagnosis of a serious or lethal fetal anomaly'? This paper focuses on one aspect that emerged from the broader research, that is the experience of pregnancy becoming public property when a fetal anomaly has been detected.

Institutional ethics approval was obtained from Charles Sturt University (Australia) and the clinic's Institutional Review Board (Washington State). The research conformed to Australia's National Health and Medical Research Council guidelines and the USA guidelines for research on vulnerable populations.

\section{Findings}

Four major themes emerged during data analysis: i) becoming public property; ii) the assumption of a healthy baby; iii) embodiment and disembodiment; and the final theme, iv) responding to the public gaze. Pseudonyms have been used to protect participant's privacy.

\section{Becoming public property: 'People treat you like public property'}


While consideration shown to pregnant women can be touching, comments on a woman's behaviour are hurtful if a woman is already feeling guilt and self-blame for not producing a 'perfect' baby:

People treat you like public property...yesterday I had two ladies let me skip in front of them to use the bathroom...I have people smile at me when I'm walking through public places. You get the other side where...if you get a coffee they assume that you're uninformed and irresponsible. Bridgette

Shared humanity provides understanding, yet there is also the invisible, the unsaid, the unrevealed. Participants experienced becoming public property and tried to protect themselves during interactions with other people:

You really have to sort it through publicly, and I've chosen not to share with total strangers what's happening with the pregnancy, just because it's not their business...someone that I know I'm going to run back into again...I think, 'Oh man, there's one more person now I have to tell'. Jasmine

Interactions between people are symbiotic and infused with meaning ${ }^{21}$. During reciprocal interactions, participants often felt pressured into sharing intimate details. Being open and exposed is made more difficult when others demand particular responses ${ }^{24}$. Participants felt relieved when people were truly present to their feelings but felt distressed when others judged them:

People go beyond 'Oh what are you having?'...if my husband would have died nobody would have asked me that many details...I've actually even had friends who felt our relationship has been jeopardised because I haven't shared as much with them. And I've tried to explain to them that emotionally, it's not helpful for me to go through the details...even close people, but we're talking even grocery store people, or people that I hardly even know, they wanna know every single thing and hardly anybody says 'I'm sorry for your loss'. Krystal

Becoming public property involved people feeling free to give unsolicited advice despite being oblivious to the invisible diagnosis. Even with knowledge of the diagnosis, people still gave 
advice, often with little understanding of the many complex issues under consideration. Bridgette described her experience:

We've gotten a lot of really well intended uninformed advice from people that don't understand the complexity of the situation, they filter it through their own experience and their limited knowledge and they try to give us advice about what they think that we should do, that's been really difficult. Bridgette

People are socialised to expect a mother to sacrifice everything for her baby ${ }^{25}$. A mother's needs are viewed as secondary and her decisions questioned. Bridgette explained her disappointment at not being able to have a normal birth to a relative who was a childbirth educator whose own births occurred naturally at home:

I really thought she would sympathise but she said to me...in a somewhat judgmental way 'Whatever's best for the baby' and...I felt defensive...who loves this baby more than I do?...but they just don't understand...what the options mean and the risks involved...you do feel like you have to defend your decisions. Bridgette

\section{The assumption of a healthy baby: 'People are so excited when they see a pregnant woman'}

The world is directly known and experienced with each person having their own perceptions, history and beliefs ${ }^{16}$. People assume that the pregnancy is normal and are taken by surprise when told the truth, and this added to participants' distress. It is probable that when people discover there is a fetal anomaly they are worried about what to say and are also frightened that this could happen to them:

People are so excited when they see a pregnant woman and they know there's going to be a new little baby. And then you tell them 'Well, there's a little defect' and you kinda feel bad ...more for them because their expression changes and they don't know how to react. Amelia 
Assuming every pregnancy is normal, people will often speak to women about the joy of parenthood. Despite the pain this caused, Jasmine chose an altruistic response:

I was on a plane the other day with a guy...for hours I had to listen to him talk about his little boy, cause he was so excited, and he didn't know what was happening with me...I don't want to...share with them and then have them feel like a creep for the rest of the time, so I just choose to talk to them and enjoy some of their joy, it's not easy. Jasmine

Being asked about the unborn baby was a constant occurrence: repeatedly reminding women of shattered hopes and dreams. Juxtaposition between the public assumption of normality and the invisible diagnosis occurred:

Oh, all day long, 'Do I have the baby's room ready?' and 'How excited am I about being a Mom?' - and all these things that are fairly difficult. Ever since I've been showing, the whole world wants to be involved in it. You go to the grocery store and they want to talk to you about it and that becomes really hard. Jasmine

People's assumptions about pregnancy and how the world should be, allowed them to ask invasive questions and judge women on their responses.

\section{Embodiment and disembodiment: 'He's not the one pregnant'}

For women, pregnancy is embodied; the fetus is always present and in late pregnancy, this presence is evident to others. For males, pregnancy is disembodied and experienced through their female partners. Tara expressed the consequences of embodiment and disembodiment:

He's not the one pregnant, so he could go out...and they don't even question anything, whereas I go out and my clients, they're like 'Oh you're pregnant...and it's sooo hard cause ...most of the time it is very nice when someone comments about your pregnancy...but in this situation...I got terrified anytime anybody would ask me about it. Tara 
Men did not become public property to the same extent because the pregnancy was not visible. This enabled men to function in public unquestioned and focus on other tasks. However, this created another dilemma:

It is so much different to be the Dad, because he's not inside me... there are still hours that'll go by where I'm working on something and I'm not really even thinking about the fact that we have a child that may have special needs... Layla, I mean she's carrying him around, she feels him, so it's so much more detached for me...I wish I could feel what she feels. Daniel

The media focuses on men's public roles as providers and supporters ${ }^{26}$. The male participants tried hard to understand their partners' experiences and fulfil the expected male role by being supportive:

I've tried to be a good guy, but...it's hard for me to really understand...the physical things...I can go drive somewhere and I can be listening to the radio and forget, not forget but remove myself from it, she can't do that. Rhys

\section{Responding to the public gaze: 'It's not like you go around telling everybody'}

The profoundness of life is tied up with relationships and the words and actions of others have the capacity to inflict pain. For participants, it was difficult to decide what to say and how to respond to questions regarding due date, gender and preparations for pregnancy:

Every day, every day...'Oh, how are you doing? You must be so excited'...it is just an everyday reminder and then you struggle with 'Okay, do I tell them? Do I not?'. Anna

Often a minimal response was given:

If it's total strangers, I don't want to get into the whole spina bifida...so I would just say that I'm due this day. Amelia 
At times, questions felt invasive and persistent. It was very difficult to tell people the baby would die, and often the easiest response was to pretend everything was fine. At a sports game another mother questioned Anna:

She was asking questions... 'Well, have you done up the nursery? How have you done it up?' So what do you say?...so I told her...that's been a struggle for me...how do you tell people?...you come up to me and you say 'Oh, how are you doing? How are you? How's your pregnancy going?' and I tell you 'Oh yeah, I'm great, I'm going to have this baby and I know he's going to die shortly after I have him'. Well, what are you going to say to me? What can I expect you to say to me...so, more often than not I just find myself just putting a smile on my face and yeah, baby's due end of February. Anna

Once the pregnancy ended, women dreaded being asked about the baby and having to explain what happened. Tara's baby had a lethal anomaly and died shortly after birth:

I tried to hide it with a few people, maybe they'll just think I'm fat or something, but it seems like it didn't work and they'd ask about when is your baby due blah, blah, blah and so I didn't tell them right away but, so I'm dreading them asking me about it later when they see that I'm not pregnant anymore, 'Oh, how's your baby?'. Tara

Some participants were very concerned about going back to work and having to tell people what happened:

Work: I've really been trying to process through how I tell them, cause I can see coming back and being in a meeting with twenty people and someone says 'Oh, I can't wait to see the baby pictures'... and what do you say? Jasmine

Participants' experiences are invisible to others and remain so unless they felt safe enough to share: 
I'm pretty cautious about who I tell, it's not the first thing I say 'Yeah I'm expecting. Oh, and he’s diagnosed with spina bifida'. You just say 'Yeah he's a boy, we're due in May'. Layla

Women were surprised at the level of interest people had in their pregnancy and what they knew:

You don't realise...how many people want to know 'Hey, how is everything going' and these are people maybe you don't come into direct contact with but they know who you are. Renata

Communication exchanges are infused with meaning and interpretation ${ }^{21}$. Invisible assumptions and understandings seriously disrupted the equilibrium of participants who began to avoid potentially painful situations:

It's not like you go around telling everybody 'Hey, I'm pregnant, baby is not going to live'...you're not going to offer that up...during the pregnancy I kind of closed myself off from all other social situations. Tara

Sometimes, dealing with other people was so hard that participants did not inform them of the diagnosis. Jasmine wanted her work to be a place where she could be 'normal', not the mother of a baby who would die. However, thinking everything was normal her colleagues wanted to give her a baby shower. Usually, this would be part of a happy routine transition to motherhood:

My team wanted to throw a shower for me...I didn't want to share with them what was going on, it was too hard, and everybody’s asking about the nursery. Jasmine

The participants' narratives told a story of relationships and interactions with others. Their words illustrate the pain and confusion caused by them becoming public property.

\section{Discussion}

For women, being treated as public property was a traumatic experience. In contrast, their male partners described feeling guilty because they could go out without being treated like public property. 
Pregnancy is embodied for women and therefore visible. Alternately, for men the pregnancy was disembodied, invisible and experienced vicariously.

Humanity exists in a shared world where interactions are laden with meaning ${ }^{21}$ and influenced by social norms ${ }^{9,10}$. People become exposed and vulnerable when they must respond to comments and questions ${ }^{24}$. Participants had no option but to be in the world interacting with others and giving these interactions meaning. Perception is embodied ${ }^{16}$ and participants can only react to the world they inhabit from a background of understandings and acculturated beliefs. Becoming public property exacerbated the pain and emotional turmoil experienced by participants.

Couples begin their pregnancy with a strong background assumption that pregnancy will result in a healthy baby. For women, there is a powerful social imperative to fit into the role of the 'good' mother who puts her baby above all else ${ }^{25,7}$. Men also endeavoured to fulfil the role they had been socialised to by providing support and solving problems. Humans are biologically and socially primed to nurture babies ${ }^{27}$ and have common expectations about proper pregnancy behaviours ${ }^{6}$. The medicalisation of pregnancy has resulted in experts prescribing, publicising and attempting to control women's behaviours ${ }^{9,10}$. This may be why people feel free to comment on the behaviour and actions of pregnant women. Public surveillance holds women responsible for pregnancy outcomes, objectifying women as mere vessels ${ }^{2,8}$.

This is difficult enough in a normal pregnancy, however after diagnosis of a fetal anomaly couples suffer from acute psychological distress ${ }^{28}$. Participants in this study indicated they were unprepared for becoming public property and its consequences such as unsolicited questions, surveillance, judgments and advice. For participants, innocuous enquiries resulted in intense emotions and a struggle between pretending all is well and the consequences of a truthful response. Becoming public property adds multiple layers of difficulties as women live through pregnancy under the public gaze. 
Limitations of this study include that all participants were in a heterosexual relationship and all but one couple were cohabitating. Although the study included participants from various cultural backgrounds; Asian, Latino and mixed race, the majority were Caucasian and all were fluent English speakers. This study requirement meant that recent immigrants and refugees were excluded from the study, limiting its applicability to different cultural groups and those who are not fluent English speakers. All participants were recruited from the one maternal-fetal medicine unit, hence limiting generalisability of findings. Although the couples were all dealing with similar situations their narratives may not be representative of the experience of all couples.

The strengths of this study include the richness of the participant's stories which illuminate a previously unknown phenomenon. Related strengths are the insights and recommendations that flow from their experience and these are outlined below.

\section{Recommendations}

Continuity of care by a known midwife is ideal and benefits women as well as men ${ }^{29,30}$. Women are empowered by midwives who see and feel with them on their journey ${ }^{31}$. Hence, midwives are ideally placed to care for couples after diagnosis of a fetal anomaly ${ }^{32,33}$. Midwives can advise women and their partners about strategies to help reduce the negative impact of becoming public property. One strategy is for parents to inform a key person who informs others. This reduces the risk of women being interrogated and helps protect parents from continually repeating information.

Participants described some of the actions that helped them cope. This included communication by email enables couples to avoid the difficulties of multiple face-to-face conversations and is a quick way to disseminate information. An experienced counsellor can provide useful emotional support. After reading the participant's experiences and considering how their care could be improved the following ideas developed: Provision of special considerations such as midwifery home visits, private antenatal classes and ensuring the entire health team are informed may be helpful. Some couples may find peer support and the opportunity to share experiences with a 
person who has had a diagnosis of a serious fetal anomaly helpful. Peer support can assist couples to develop the coping skills needed for dealing with the public gaze. Good midwifery support and guidance may help women feel less isolated and less likely to avoid public situations. Midwives are privileged to accompany parents through the devastation of diagnosis, the intense experience of meeting baby and the postpartum period. Midwives need to use supportive strategies to reduce the negative impact of the public gaze on couples who continue pregnancy following diagnosis of a fetal anomaly.

\section{Conclusion}

It is common for pregnant women to be treated as public property and this has positive as well as negative aspects. Special consideration may be given to women who are pregnant. However, serious negative consequences occur when women are subject to condemnation if their behaviours do not fit socially constructed norms, exacerbating concerns that they may have somehow caused the fetal anomaly. For couples in this study, becoming public property and the general assumption that pregnancy will result in a healthy baby only magnified their distress. Well informed midwives can help couples develop strategies to reduce the negative impact of becoming public property following the diagnosis of a fetal anomaly during pregnancy. 


\section{References}

1. Whittemore R, Knafl K. The integrative review: updated methodology. Journal of Advanced Nursing. 2005;52(5):546-53.

2. Bailey L. Gender Shows: First-Time Mothers and Embodied Selves. Gender and Society. 2001;15(1):110-29.

3. D'Enbeau S, Buzzanell PM. Caregiving and female embodiment: scrutinizing (professional) female bodies in media, academe, and the neighbourhood bar. Women and Language 2010;33(1):29-52.

4. Elvey A. The material given: bodies, pregnant bodies and earth. Australian Feminist Studies 2003;18(41):199-209.

5. Fox R, Heffernan K, Nicolson P. 'I don't think it was such an issue back then': changing experiences of pregnancy across two generations of women in south-east England. Gender, Place and Culture 2009;16(5):553-68.

6. Longhurst R. 'Corporeographies' of pregnancy: 'bikini babes'. Environment and Planning D: Society and Space 2000;18:453-72.

7. Paff Ogle JP, Tyner KE, Schofield-Tomschin S. Watching Over Baby: Expectant Parenthood and the Duty to Be Well. Sociological Inquiry. [Article]. 2011;81(3):285-309.

8. Rubin L, Steinberg J. Self-Objectification and Pregnancy: Are Body Functionality Dimensions Protective? Sex Roles. [Article]. 2011;65(7/8):606-18.

9. Carter SK. Gender Performances During Labour and Birth in the Midwives Model of Care. Gend Issues. 2009:26:205-23.

10. Popiel JJ. Making Mothers: The Advice Genre and the Domestic Ideal, 1760-1830. Journal of Family History. 2004:29(4):339-50.

11. Bainbridge J. Unsolicited advice: a rite of passage through your first pregnancy. British Journal of Midwifery 2006;14(5):265.

12. Roush A, Sullivan P, Cooper R, McBride JW. Perinatal hospice. Newborn and Infant Nursing Reviews 2007;7(4):216-21. 
13. Chitty LS, Barnes CA, Berry C. Continuing with pregnancy after a diagnosis of lethal abnormality: experience of five couples and recommendations for management. British Medical Journal 1996;313(7055):478-80.

14. Locock L, Crawford J, Crawford J. The parents' journey: continuing a pregnancy after a diagnosis of Patau’s syndrome. British Medical Journal 2005;331(7526):1186-9.

15. Ramer-Chrastek J, Thygeson MV. A perinatal hospice for an unborn child with a life-limiting condition. International Journal of Palliative Nursing 2005;11(6):274-6.

16. Merleau-Ponty M. Phenomenology of perception. Trans. C Smith. Routledge and Kegan Paul, 1945/1962.

17. De Witt L, Ploeg J. Critical appraisal of rigour in interpretive phenomenological nursing research. Journal of Advanced Nursing. [Article]. 2006;55(2):215-29

18. Lopez KA, Willis DG. Descriptive versus interpretive phenomenology: their contributions to nursing knowledge. Qualitative Health Research. 2004;14(5):726-35.

19. Thomas S, P. Through the lens of Merleau-Ponty: advancing the phenomenological approach to nursing. Nursing Philosophy. 2005;6:63-76.

20. Mapp T. Understanding phenomenology: the lived experience. British Journal of Midwifery 2008;16(5):308-11.

21. Hass L. Merleau-Ponty’s philosophy. Bloomington: Indiana University Press; 2008.

22. QSR NVivo 7. QSR NVivo 7. 2006.

23 McCreight BS. Perinatal loss: a qualitative study in Northern Ireland. Omega: Journal of Death and Dying 2008;57(1):1-19.

24 Davis-Floyd R. Windows in space and time: a personal perspective on birth and death. Birth 2003;30(4):272-7.

25 Malacrida C. Performing motherhood in a disablist world: dilemmas of motherhood, femininity and disability. International Journal of Qualitative Studies in Education. 2009;22(1 January-February):99-117. 
26 Johnston DD, Swanson DH. Invisible mothers: a content analysis of motherhood ideologies and myths in magazines. Sex Roles 2003;49(1/2):21-33.

27 DiPietro JA, Irizarry RA, Costigan KA, Gurewitsch ED. The psychophysiology of the maternal-fetal relationship. Psychophysiology. 2004;41:510-20.

28 Van der Zalm J, Byrne P. Seeing baby: women’s experience of prenatal ultrasound examination and unexpected fetal diagnosis. Journal of Perinatology 2006;26:403-8.

29 Dahlen H, Jackson M, Schmied V, Tracy S, Priddis H. Birth centres and the national maternity services review: response to consumer demand or compromise? Women and Birth 2011;24(4):165-72.

30 Hildingsson I, Cederlof L, Widen S. Fathers' birth experience in relation to midwifery care. Women and Birth 2011;24(3):129-36.

31 Lundqvist A, Nilstun T, Dykes A. Both empowered and powerless: mothers' experiences of professional care when their newborn dies. Birth 2002;29(3):192-9.

32 Fenwick J, Jennings B, Downie J, Butt J, Okanaga M. Providing perinatal loss care: satisfying and dissatisfying aspects for midwives. Women and Birth 2007;20(4):153-60.

33 Lalor JG, Devane D, Begley CM. Unexpected diagnosis of fetal abnormality: women's encounters with caregivers. Birth 2007;34(1):80-8. 